OPEN ACCESS

Edited by:

Aaron Smith

Louisiana State University, USA

Reviewed by:

Dimah Habash,

Securewheat Consultancy, UK

Huixia Shou,

Zhejiang University, China

*Correspondence:

Günter Neumann

gd.neumann@t-online.de

Specialty section:

This article was submitted to

Plant Nutrition,

a section of the journal

Frontiers in Plant Science

Received: 11 September 2015 Accepted: 18 December 2015

Published: 20 January 2016

Citation:

Neumann G (2016) The Role of Ethylene in Plant Adaptations for Phosphate Acquisition in Soils A Review. Front. Plant Sci. 6:1224.

doi: 10.3389/fpls.2015.01224

\section{The Role of Ethylene in Plant Adaptations for Phosphate Acquisition in Soils - A Review}

\author{
Günter Neumann* \\ Nutritional Crop Physiology, Institute of Crop Science, University of Hohenheim, Stuttgart, Germany
}

Although a role of ethylene in the regulation of senescence and plant stress responses in general has a long history, a possible involvement in the regulation of adaptive responses to nutrient deficiencies has been mainly investigated since the last two decades. In the case of plant responses to phosphate $\left(\mathrm{P}_{\mathrm{i}}\right)$ starvation, ethylene was identified as a modulator of adaptive responses in root growth and morphology. The molecular base of these adaptations has been elucidated in supplementation studies with ethylene precursors and antagonists, as well as analysis of mutants and transgenic plants with modified ethylene biosynthesis and responsiveness, using mainly Arabidopsis thaliana as a model plant. However, increasing evidence suggests that apart from root growth responses, ethylene may be involved in various additional plant adaptations to $P_{i}$ limitation including $P_{i}$ mobilization in the rhizosphere, $P_{i}$ uptake and internal $P_{i}$ recycling. The ethylene-mediated responses are frequently characterized by high genotypic variability and may partially share common pathways in different nutrient limitations.

Keywords: ethylene, root growth, root morphology, phosphate deficiency, phosphate acquistion

\section{INTRODUCTION}

Among the wide range of phosphorus $(\mathrm{P})$ forms in soils, inorganic phosphate anions $\left(\mathrm{P}_{\mathrm{i}}\right)$ are taken up exclusively by plant roots. However, due to limited solubility, $\mathrm{P}$ is the macronutrient with the lowest plant availability in soils. Even in well-fertilized soils, on average only $20 \%$ of the fertilizer input are utilized by plants since the majority of fertilizer $P_{i}$ is prone to $P_{i}$ fixation and incorporation into organic $P_{i}$ forms comprising $20-80 \%$ of total soil P. (Richardson, 1994; Holford, 1997). Therefore, higher plants are strongly dependent on specific adaptations to acquire $P_{i}$ in sufficient amounts. Adaptive responses toward improved spatial $P_{i}$ acquisition comprise stimulation of root growth, increased formation of fine root structures (lateral roots, root hairs) (Figure 1), preferential root development in the top soil with the highest $\mathrm{P}$ content (Lynch and Brown, 2001) or stimulation of lateral root growth in nutrient patches rich in $\mathrm{P}$ and also $\mathrm{N}$ (Forde and Lorenzo, 2001). Modifications of the rhizosphere chemistry, such as rhizosphere acidification, secretion of organic metal-chelators (carboxylates, phenolics) and phosphohydrolases (acid phosphatase, phytase) increase the solubility and plant availability of $\mathrm{P}_{\mathrm{i}}$ in the rhizosphere (Neumann and Römheld, 2002, 2007). The formation of so-called cluster roots (CR; Figure 2) within the Proteaceae, Casuarinaceae, Myrtaceae, and Fabaceae (Dinkelaker et al., 1995; Neumann and Martinoia, 2002), or dauciform roots in Cyperaceae (Playsted et al., 2006) are among the most specialized root-morphological adaptations to promote the secretion of Pi-mobilizing root 


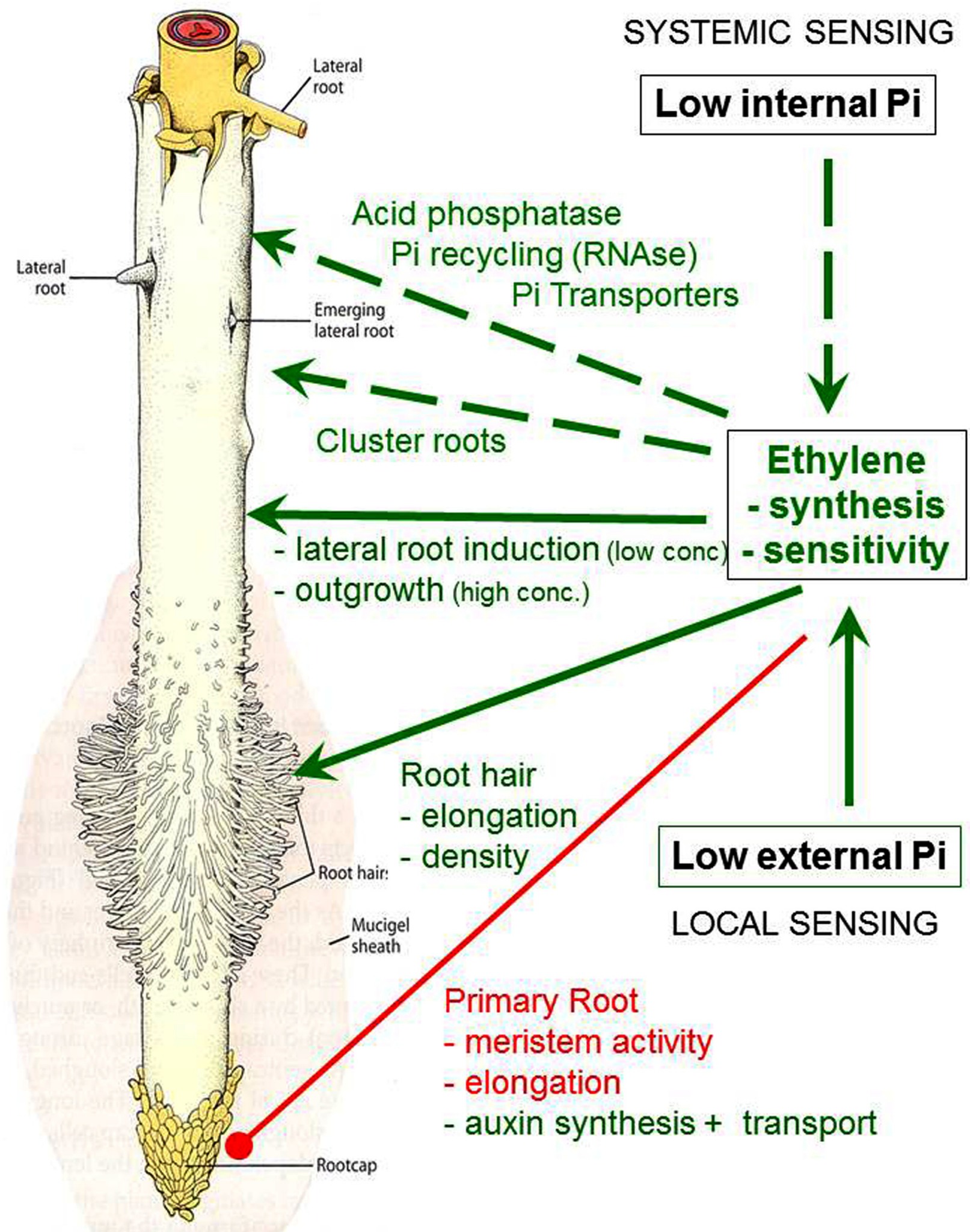

FIGURE 1 | Adaptive responses to $\mathbf{P}_{\mathbf{i}}$ limitation in plant roots modulated by ethylene. Green: stimulation; red: inhibition. 

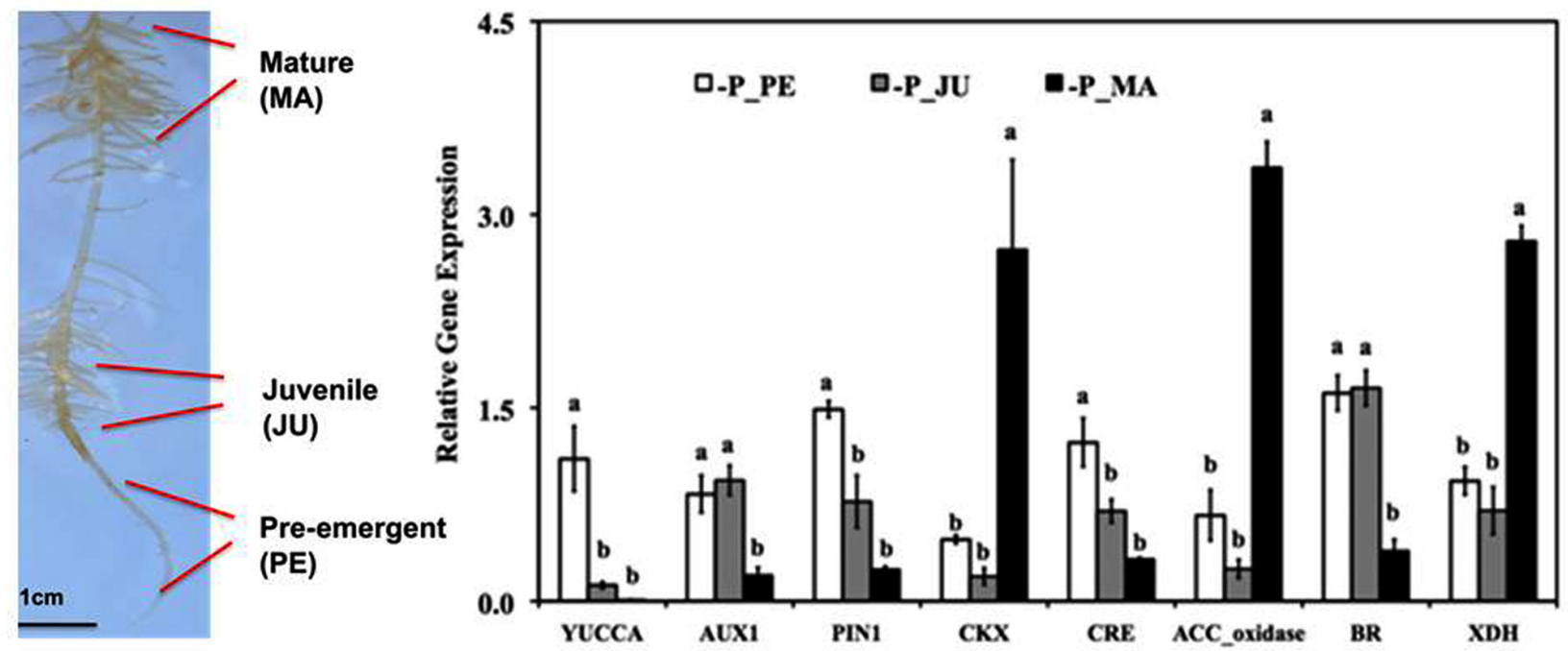

FIGURE 2 | Expression pattern of hormone-related genes during cluster root (CR) development in Lupinus albus grown for 20 days without $P_{\mathbf{i}}$ supply and evaluated by quantitative real time PCR (RT-qPCR). Genes are involved in auxin biosynthesis (YUCCA), auxin transport (AUX1, PIN1), cytokinin degradation $(\mathrm{CKX})$, cytokinin receptors (CRE), ethylene biosynthesis (ACC_oxidase), brassinosteroid biosynthesis (BR), and RNA degradation associated with nitric oxide formation $(X D H)$. The gene expression level is indicated relative to reference genes. Data represent means \pm SE $(n=2-3)$. Different lowercase letters denote significant differences $(P<0.05)$. PE, pre-emergent stage; JU, juvenile root clusters; MA, mature root clusters (modified after Wang et al., 2014b). The photo shows the different developmental stages of CRs used for RNA isolation: PE, pre-emergent stage; JU, juvenile cluster; MA, mature cluster.

exudates. The expression of high affinity $\mathrm{P}_{\mathrm{i}}$ uptake systems provides the ability for efficient exploitation of the rhizosphere solution even at low $\mathrm{P}_{\mathrm{i}}$ levels, hardly exceeding concentrations of $10 \mu \mathrm{M}$ (Bieleski, 1973) even in well-fertilized soils. Also symbiotic associations with mycorrhizal fungi are frequently established as adaptive responses for improved spatial (arbuscular and ectomycorrhizal fungi) and chemical acquisition (mainly ectomycorrhizal fungi) of soil P forms (Neumann and Römheld, 2002).

Among the wide range of regulatory factors involved in the induction of adaptive responses to $\mathrm{P}_{\mathrm{i}}$ limitation, there is increasing evidence that these processes are modulated also by ethylene as important regulator. In many studies, the role of ethylene has been investigated by exogenous application of precursors and antagonists of ethylene synthesis and signal transduction and by expression analysis of genes involved in ethylene biosynthesis, signaling and ethylene responses. Other strategies comprise the analysis of mutants and transgenic plants with modified synthesis, signaling and reception of ethylene, most frequently using Arabidopsis thaliana as model plant (Nagarajan and Smith, 2011).

\section{ETHYLENE AND ROOT GROWTH RESPONSES}

The involvement of ethylene in regulation of root growth has been postulated already in early studies by Chadwick and Burg (1967) on root geotropism and Smith and Russell (1969) on root growth responses under oxygen limitation, including also interactions with auxin (Chadwick and Burg, 1967, 1970).
Meanwhile it is generally accepted that ethylene influences root growth in a biphasic manner with stimulatory effects, e.g., on lateral root formation induced by low ethylene concentrations, triggering both, synthesis and signaling of auxins, as indicated by analysis of Arabidopsis mutants affected in auxin signaling and ethylene-induced auxin synthesis (Stepanova et al., 2005; Ivanchenko et al., 2008). The ethylene-induced modifications of auxin synthesis and transport contribute to the formation of auxin gradients necessary for the induction of lateral root primordia in the pericycle opposite the prototoxylem poles (Fukaki and Tasaka, 2009).

By contrast, high ethylene concentrations exert inhibitory effects on lateral root formation, as demonstrated by Negi et al. (2008), showing that both, overproduction of ethylene by high external application of the ethylene precursor 1aminocyclopropane-1-carboxylic acid (ACC) or by the eto1 mutation, inhibited lateral root formation in Arabidopsis. On the other hand, lateral root formation was stimulated in the etr1 (ethylene triple response1) or ein2 (ethylene insensitive2) mutations, blocking ethylene responses (Negi et al., 2008). Similar to lateral root formation promoted by low levels of ethylene, ethylene/auxin interactions seem to be involved also in the inhibitory effects on root growth induced by high ethylene concentrations, stimulating both, acropetal and basipetal auxin transport with involvement of the AUX1 influx carrier as indicated by an ethylene-insensitive aux1-7 mutant of Arabidopsis (Negi et al., 2008), as well as PIN3 and PIN7 efflux transporters (Lewis et al., 2011). The ethylene-mediated stimulation of auxin transport may inhibit lateral root formation by a reduction of auxin accumulation in the protoxylem pericycle, required for initiation of lateral root primordia (Fukaki and 
Tasaka, 2009). Interestingly, high ethylene concentrations exerted inhibitory effects on formation of new lateral root primordia but stimulated outgrowth of already existing primordia (Ivanchenko et al., 2008). In primary roots of Arabidopsis, also a massive ethylene-induced stimulation of auxin synthesis in the root tip has been observed (Ruzicka et al., 2007; Swarup et al., 2007) with inhibitory effects on root growth, which may at least partially be attributed to a reduced extensibility of the cell wall due to inhibition of the auxin-dependent plasmalemma $\mathrm{H}^{+}$-ATPase and formation of reactive oxygen species (ROS), promoting cross-linking of cell walls by hydroxyproline-rich glycoproteins in response to high auxin concentrations. Increased ethylene levels are also able to affect the activity of the primary root meristem, probably by interaction with jasmonic acid (ChaconLopez et al., 2011), inducing a determinate developmental program with arrested cell division and promotion of cell differentiation.

\section{ADAPTIVE RESPONSES TO $P_{i}$ LIMITATION - SPATIAL $P_{\mathrm{i}}$ ACQUISITION}

Measurements of ethylene production, inhibitor studies (Borch et al., 1999; Lynch and Brown, 2001; Li et al., 2009), analyses of mutants in gene expression of the ethylene bio-synthetic pathway (Tsuchisaka and Theologis, 2004; O'Rourke et al., 2013; Wang et al., 2014a) revealed promotion of ethylene synthesis and/or enhanced ethylene sensitivity (Figure 1), induced by $\mathrm{P}_{\mathrm{i}}$ limitation in higher plants (He et al., 1992; Kim et al., 2008). These responses seem to be expressed in a highly tissue-specific and developmental stage-dependent manner. Accordingly, Kim et al. (2008) reported up-regulation of ethylene production in shoots but not in roots of $\mathrm{P}_{\mathrm{i}}$-deficient tomato and no effects in Petunia with the conclusion that modifications in ethylene sensitivity are more important in latter cases. As another example, Wang et al. (2014a) recorded up-regulation of the ethylene biosynthesis gene encoding ACC oxidase in 1-2 cm sub-apical lateral root zones just prior emergence of secondary laterals during CR development in Pi-deficient white lupin (Lupinus albus L.). Gene expression of ACC oxidase declined after outgrowth of the secondary laterals, followed by a massive increase again during further development of the root clusters (Figure 3).

The $\mathrm{P}_{\mathrm{i}}$ deficiency-induced changes in ethylene accumulation and ethylene responsiveness are involved in adaptive modifications of root growth toward improved $\mathrm{P}$ acquisition. Typical patterns comprise a reduction of primary root growth, associated with an increase in lateral root development (Figure 1) promoting the development of a shallower root system for exploitation of top soil layers with the highest $\mathrm{P}$ availability (Linkohr et al., 2002; Lopez-Bucio et al., 2002; Sanchez-Calderon et al., 2006; Svistoonoff et al., 2007). Similarly, the angle of basal lateral roots in common bean can be modulated by increased sensitivity to ethylene in response to low $\mathrm{P}_{\mathrm{i}}$ supply, to direct lateral root development into the upper soil layers (Basu et al., 2007). However, the described ethylene-mediated root growth responses to $\mathrm{P}$ limitation cannot be generalized and exhibit high genotypic variability. Testing 73 ecotypes of Arabidopsis thaliana revealed $\mathrm{P}$ deficiency-induced inhibition of primary root elongation only for $50 \%$ of the accessions (Chevalier et al., 2003). A survey of 14 dicots and monocots in hydroponics showed that all tested species had the same degree of primary root elongation independent of the $\mathrm{P}_{\mathrm{i}}$-nutritional status (Narayanan and Reddy, 1982), and many plant species even exhibit root elongation under low $-\mathrm{P}_{\mathrm{i}}$ conditions (Niu et al., 2012). Also the formation of shallower root systems in common bean is a heritable trait with genotypic variability, which has already been exploited for breeding programs to promote top soil foraging for improved $\mathrm{P}_{\mathrm{i}}$ acquisition (Lynch and Brown, 2012).

One of the earliest detectable modifications of root morphology in response to $\mathrm{P}_{\mathrm{i}}$ starvation is an increased number and length of root hairs (Bates and Lynch, 2001; Ma et al., 2001; Jain et al., 2007) as an important adaptation for improved spatial acquisition of available $\mathrm{P}_{\mathrm{i}}$ in the rhizosphere (Figures 1 and 2) with particular importance for plant species unable to form mycorrhizal associations. Accordingly, length of root hairs was inversely correlated with the degree mycotrophy in different plant species (Schweiger et al., 1995). However, due to secretory properties (protons, organic metal chelators, mucilage) and surface extension, the length and the density of root hairs also determines root soil contact and chemical modifications of the rhizosphere toward improved solubilization of nutrients (Playsted et al., 2006; Haling et al., 2013; Abrahão et al., 2014).

Based on the observation that in contrast to Fe deficiency, the number of root hairs in Arabidopsis under $\mathrm{P}_{\mathrm{i}}$ limitation was not affected by application of ethylene anatagonists and also not in the ethylene-insensitive ein 2 and the ethyleneresitant etr1 mutants, Schmidt and Schikora (2001) concluded that the development of extra root hairs in response to $\mathrm{P}_{\mathrm{i}}$ limitation does not appear to require ethylene signaling. However, treatments with the ethylene precursor ACC promoted root hair elongation, which was inhibited by ethylene antagonists (Zhang et al., 2003). Moreover, root hair length was reduced in various ethylene-response mutants as compared with the wild type under $\mathrm{P}$ limitation but not with sufficient $\mathrm{P}_{\mathrm{i}}$ supply (Cho and Cosgrove, 2002; Zhang et al., 2003), suggesting that ethylene is involved in the regulation of $\mathrm{P}_{\mathrm{i}}$ deficiencyinduced root hair elongation (Figure 1). Moreover, ethylene increased also the density of root hairs by shortening trichoblast cells to increase the number of $\mathrm{H}$ cells per unit root length (Zhang et al., 2003). Apart from the hormone-dependent metabolic regulation, root hair development in response to $\mathrm{P}_{\mathrm{i}}$ limitation also shows marked genotypic variations and improved $\mathrm{P}$ acquisition in cultivars with long root hairs has been documented for barley (Gahoonia et al., 1997; Haling et al., 2013) and Phaseolus vulgaris where a combination of ethylene-modulated root traits, such as long root hairs and a shallow root system was particularly efficient (Miguel et al., 2015).

Interestingly, the ethylene mediated responses of root growth to $\mathrm{P}_{\mathrm{i}}$ limitation as described so far, seem to be largely independent from a low P-nutritional status of the plant as a systemic signal, 

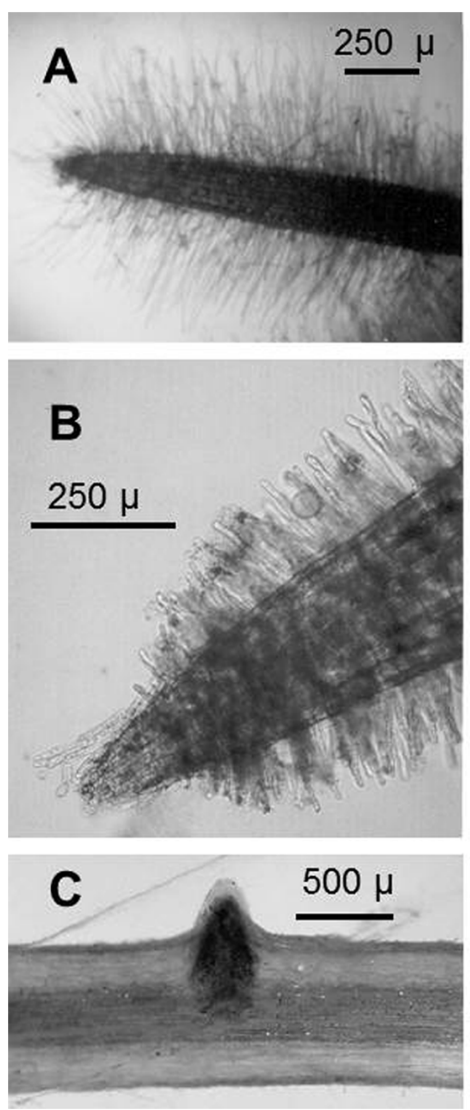

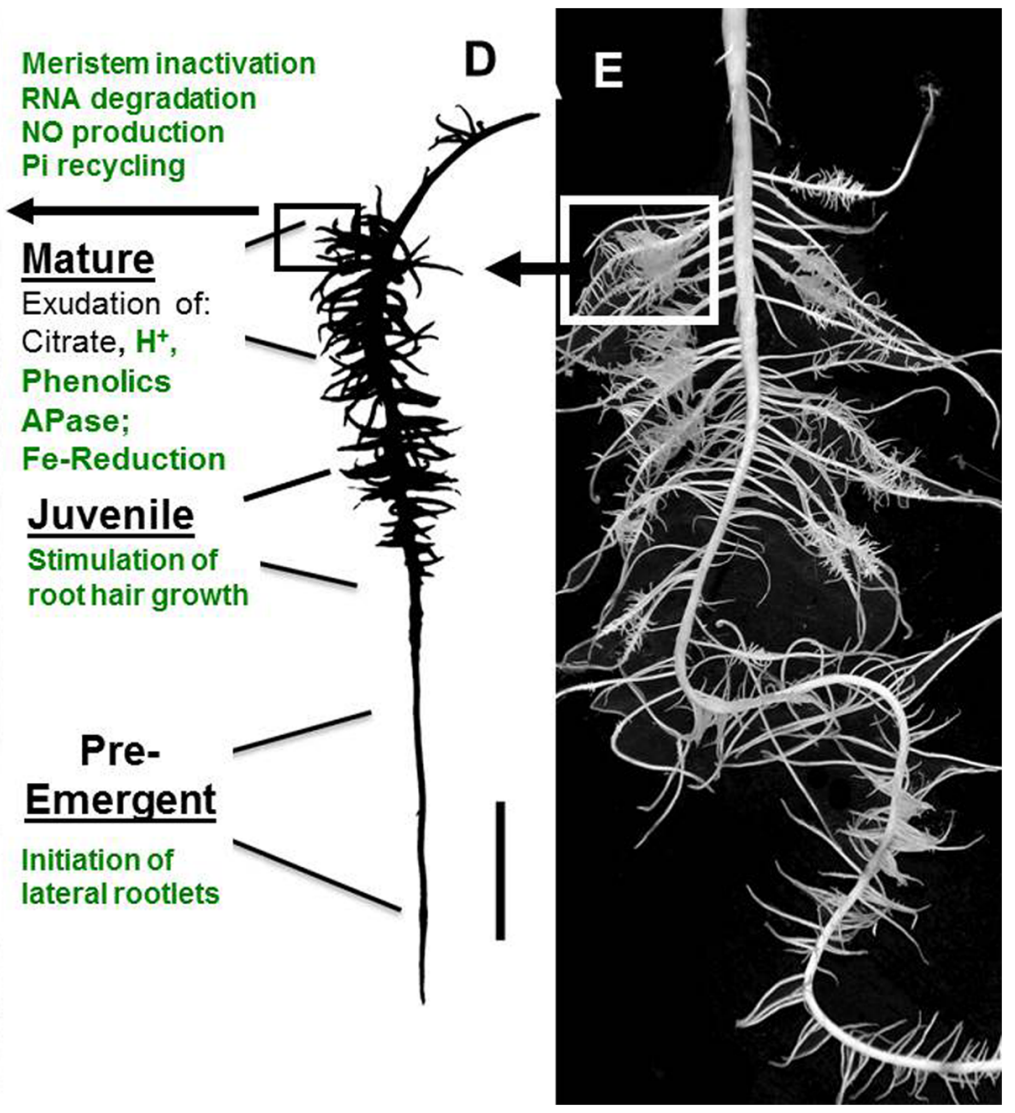

FIGURE 3 | Stages of CR development in $\mathbf{P}_{\mathrm{i}}$-deficient white lupin (Lupinus albus $\mathbf{L}$.). Characteristic processes in the different root zones potentially modulated by ethylene are marked in green. (A) Single second order lateral rootlet of a MA root cluster, densely covered with root hairs. (B) Single lateral rootlet of an outgrowing juvenileJU root cluster with growing root hairs. (C) Outgrowth of a lateral rootlet primordium. (D) Root clusters in different developmental stages along a first-order lateral root; (E) Root system of $\mathrm{P}_{\mathrm{i}}$-deficient white lupin with CRs development. PE, pre-emergent stage; JU, juvenile cluster; MA, mature cluster. (Figure modified after Wang et al., 2014b).

and a low $\mathrm{P}_{\mathrm{i}}$ level in the external rooting medium seems to be sufficient for the induction (Thibaud et al., 2010; Nagarajan and Smith, 2011). The local sensor is currently unknown but it seems to be plausible that high affinity $\mathrm{P}$ transporters, located in the plasma membrane of epidermal cells in roots and root hairs, could express a double function as transporters and receptors (transceptors) as already shown for the yeast Pho84p high-affinity $\mathrm{P}_{\mathrm{i}}$ transporter (Popova et al., 2010) or the Arabidopsis nitrate transporter CHL1/NRT1.1 with functions as transporter and sensor for nitrate in the external medium (Ho et al., 2009). The low $\mathrm{P}_{\mathrm{i}}$ status of the rooting medium is most probably sensed in the apoplast of the primary root tip (Svistoonoff et al., 2007) and a P5-type ATPase (PDR2) interacting with the SCARECROW transcription factor and multi-copper oxidases (LPR1/LPR2) in the ER of the root tip meristem have been characterized as components of the sensing system. After sensing the local $\mathrm{P}_{\mathrm{i}}$ status at the primary root tip, the information of $\mathrm{P}_{\mathrm{i}}$ depletion at the roots is translocated via xylem transport to the shoot and may involve $\mathrm{P}_{\mathrm{i}}$, strigolactones, and cytokinins as signal molecules (recently reviewed by Chiou and Lin (2011) and Zhang et al. (2014).

\section{ADAPTIVE RESPONSES TO $\mathbf{P}_{\mathrm{i}}$ LIMITATION - $P_{\mathrm{i}}$ MOBILIZATION}

Apart from functions in adaptive modulation of root morphology and root architecture for improved spatial acquisition of available soil $\mathrm{P}_{\mathrm{i}}$, there is also increasing evidence for a role of ethylene in root-induced adaptations to increase the chemical availability of $\mathrm{P}_{\mathrm{i}}$ in the rhizosphere. A large proportion of soil $\mathrm{P}_{\mathrm{i}}$ (up to $80 \%$ ) is usually sequestered in organic binding forms, requiring mineralization by enzymatic hydrolysis prior to plant uptake (Richardson, 1994; Holford, 1997). Accordingly, both, soil microorganisms and plant roots are able release phosphohydrolases (e.g., acid phosphatases, alkaline phosphatases, phytases, nucleases) to acquire or recycle $\mathrm{P}_{\mathrm{i}}$ from organic binding forms. Particularly root secretion of acid phosphatases is stimulated as a response to $\mathrm{P}_{\mathrm{i}}$ limitation in many plant species (Neumann and Römheld, 2007) and ethylene signalling seems to be involved in the up-regulation of intracellular and secretory acid phosphatases (Figure 1), both, at the level of transcription and enzyme activity as indicated by precursor/inhibitor experiments and 
analysis of the ethylene insensitive ein2-5 and the ethyleneoverproducing hps 2 mutant (Lei et al., 2011; Li et al., 2011).

In contrast to the adaptive responses in root growth, the up-regulation of acid phosphatases is induced systemically by a low internal $\mathrm{P}_{\mathrm{i}}$ nutritional status of the plant. Other systemic, potentially ethylene-mediated responses comprise the up-regulation of ribonuclease genes (RNS1), intracellular acid phosphatases (ACP5) and $\mathrm{P}_{\mathrm{i}}$ transporters $(\mathrm{Pht} 1,4)$ involved in remobilization and re-translocation of $\mathrm{P}_{\mathrm{i}}$ from $\mathrm{RNA}$ and other organic $\mathrm{P}$ compounds in senescing organs (Figures $\mathbf{1}$ and 2), during programmed cell death and also in response to $\mathrm{P}_{\mathrm{i}}$ limitation (Thibaud et al., 2010; Nagarajan and Smith, 2011). Accordingly, increased ethylene responsiveness has been implicated also in the formation of lysigenic aerenchyma in $\mathrm{P}_{\mathrm{i}}$-deficient maize roots (He et al., 1992, 1994) as a strategy for $\mathrm{P}_{\mathrm{i}}$ recycling.

\section{CLUSTER ROOTS}

The formation of cluster roots (CR) belongs to the most specialized adaptations for mobilization of sparingly soluble $\mathrm{P}_{\mathrm{i}}$ sources in soils (Figure 2). Although CRs have been detected in various plant families such as Proteaceae, Casuarinaceae, Mytaceae, Fabaceae, and others, white lupin so far represents the best-characterized model plant with respect to regulatory aspects of CR development and CR function. CRs are bottlebrush like structures formed by short second-order laterals with determinate growth and densely covered with root hairs (Dinkelaker et al., 1995; Neumann and Martinoia, 2002). Thereby, the largely increased surface area enables a concentrated release of organic metal chelators (citrate, malate, phenolics), ectoenzymes (acid phosphatases), protons and reductive changes in the rhizosphere, mediating the mobilization of sparingly soluble soil phosphates but also other nutrients, such as $\mathrm{Fe}, \mathrm{Mn}, \mathrm{Zn}$, and Mo (Gardner et al., 1983; Dinkelaker et al., 1997, Neumann and Römheld, 2007). In the past, only a few studies addressed a possible involvement of ethylene in CR development, mainly with inhibitor studies and measuring ethylene evolution from the whole root system (Gilbert et al., 2000; Zaid et al., 2003). More recently, transcriptomics and gene expression studies revealed considerable variation in the expression of genes encoding ethylene bio-synthetic enzymes (ACC oxidase, ACC synthase) during CR development (O'Rourke et al., 2013; Wang et al., 2014a,b).

In the $1.2 \mathrm{~cm}$ subapical root zones of first-order laterals, prior to the emergence of the second-order lateral cluster rootlets, ethylene biosynthesis genes are moderately up-regulated together with genes involved in auxin biosynthesis (YUCCA) and transport (AUX1, PIN1), synthesis of brassinosteroids, and cytokinin receptors (Figure 3; Wang et al., 2014a,b), in accordance with the postulated role of these hormonal factors in formation of auxin gradients required for priming of pericycle cells for induction of the lateral rootlet primordia
(Fukaki and Tasaka, 2009). However, in contrast to ethylenemediated modifications of root growth under $\mathrm{P}_{\mathrm{i}}$ limitation discussed so far (including growth inhibition of the primary root and lateral root proliferation), CR formation is largely induced systemically determined mainly by the $\mathrm{P}_{\mathrm{i}}$-nutritional status of the shoot (Marschner et al., 1987; Shane et al., 2003). Accordingly, induction of CRs in $\mathrm{P}_{\mathrm{i}}$-deficient white lupin can be suppressed almost completely by foliar $\mathrm{P}_{\mathrm{i}}$ application (Marschner et al., 1987). More recently, sucrose has been identified as important shoot-borne signal, triggering the formation of CRs (Zhou et al., 2008; Wang et al., 2015) mediated by the welldocumented increased shoot-to root translocation of sucrose under $\mathrm{P}_{\mathrm{i}}$ limitation (Hammond and White, 2008, 2011; Wang et al., 2015). Even in $\mathrm{P}_{\mathrm{i}}$-sufficient lupin plants cultivated with $\mathrm{P}_{\mathrm{i}}$ concentrations suppressive for $\mathrm{CR}$ formation, external application of sucrose to the rooting medium induced the formation of CRs in a concentration dependent manner to a similar or even higher extent than in P-deficient plants (Wang et al., 2015). Both, $\mathrm{P}_{\mathrm{i}}$ deficiency-induced CR formation and sucrose-induced formation of CRs under sufficient $\mathrm{P}_{\mathrm{i}}$ supply are completely suppressed by the ethylene biosynthesis inhibitor $\mathrm{CoCl}_{2}$ (Wang et al., 2014b). Moreover, in many other plant species it has been shown that external sucrose supply increases ethylene production in a concentration-dependent manner with effects on various processes, such as anthocyanin production, flowering, and fruit ripening (Philosoph-Hadas et al., 1985; Kobayashi and Saka, 2000; Jeong et al., 2010) and sucrose concentrations increased in the sub-apical root zones of first-order laterals in P-deficient white lupin (Wang et al., 2015). These findings raise the question whether sucrose as a shoot-borne signal exerts its stimulatory effects on CR formation via stimulation of ethylene biosynthesis. However, during outgrowth of the CR primordia in the juvenile (JU) stage of CR development, expression of transcripts involved in ethylene biosynthesis (ACC oxidase) and auxin synthesis and transport transiently declined, followed by a massive increase of ACC oxidase gene expression during cluster-root maturation (Figure 3; Wang et al., 2014a,b). This is associated with a range of metabolic and developmental modifications (Wang et al., 2014a) known to be mediated by ethylene signaling also in other plant species comprising: (i) initiation of determinate growth of the lateral rootlets by inactivation of the root tip meristem including interactions with jasmonic acid (ChaconLopez et al., 2011; Wang et al., 2014a); (ii) formation of long, densely spaced root hairs (Cho and Cosgrove, 2002; Neumann and Martinoia, 2002; Zhang et al., 2003); (iii) increased expression of root secretory acid phosphatase (Massonneau et al., 2001; Lei et al., 2011); (iv) a massive decline (80\%) of total RNA contents (Massonneau et al., 2001) associated with up-regulation of ribonuclease genes and $\mathrm{P}_{\mathrm{i}}$ transporters (Figure 2) involved in remobilization and re-translocation of $\mathrm{P}_{\mathrm{i}}$ from RNA degradation to the young, actively growing root zones (Thibaud et al., 2010; Nagarajan and Smith, 2011; Wang et al., 2014a,b); (v) the massive RNA degradation during $\mathrm{CR}$ maturation results in the formation of $\mathrm{NO}$ as a side product.(Wang et al., 2010). Together with ethylene, NO may be involved in the induction of the FIT transcription factor as 
a central regulator of the coordinated Fe deficiency responses in strategy I plants (Hindt and Guerinot, 2012), which surprisingly was similarly expressed in mature CRs of white lupin even under Fe-sufficient conditions (Wang et al., 2014a) including also the up-regulation of the plasma membrane ferric reductase system (FRO2) and the FeII transporter (IRT1). Interestingly many adaptations of CRs toward improved $\mathrm{P}_{\mathrm{i}}$ acquisition, such as root hair proliferation, proton extrusion, exudation of phenolic compounds with metal-chelating properties and increased ferric reductase activity at the root surface are also part of the strategy I mechanism for $\mathrm{Fe}$ acquisition (Neumann and Römheld, 2007). Since lupins are naturally adapted to moderately acidic soils frequently characterized by $\mathrm{P}_{\mathrm{i}}$ fixation on iron amd aluminum oxides/hydroxides, the expression of mechanisms for $\mathrm{Fe}$ acquisition may be beneficial also for mobilization of sparingly soöuble $\mathrm{Fe}-\mathrm{P}$ forms even at low soil $\mathrm{pH}$, where $\mathrm{Fe}$ availability is usually not a problem. Consequently, in white lupin responses to Fe deficiency and to $\mathrm{P}$ limitation may at least partially share the same ethylene-dependent signaling pathways. Also in Arabidopsis, an interplay of strategies for $\mathrm{P}$ and $\mathrm{Fe}$ acquisition is suggested by increased $\mathrm{Fe}$ accumulation in response to $\mathrm{P}$ limitation (Mission et al., 2005; Hirsch et al., 2006; Ward et al., 2008) However, in contrast to white lupin, this was associated with a down-regulation of the IRT1 tansporter and increased expression of FER1 encoding a Fe storage protein (Mission et al., 2005). This was interpreted as a protective mechanism to counteract Fe toxicity. In white lupin, despite up-regulation of the strategy I mechanism for Fe acquisition, no excessive Fe accumulation was observed in response to $\mathrm{P}_{\mathrm{i}}$ limitation (Wang et al.,

\section{REFERENCES}

Abrahão, A., Lambers, H., Sawaya, A. C., Mazzafera, P., and Oliveira, R. S. (2014). Convergence of a specialized root trait in plants from nutrient-impoverished soils: phosphorus-acquisition strategy in a nonmycorrhizal cactus. Oecologia 176, 345-355. doi: 10.1007/s00442-014-3033-4

Basu, P., Pal, A., Lynch, J. P., and Brown, K. M. (2007). A novel image- analysis technique for kinematic study of growth and curvature. Plant Physiol. 145, 305-316. doi: 10.1104/pp.107.103226

Bates, T. R., and Lynch, J. P. (2001). Root hairs confer a competitive advantage under low phosphorus availability. Plant Soil 236, 243-250. doi: 10.1023/A:1012791706800

Bieleski, R. L. (1973). Phosphate pools, phosphate transport, and phosphate availability. Annu. Rev. Plant Physiol. 24, 225-252. doi: 10.1146/ annurev.pp.24.060173.001301

Borch, K., Bouma, T. J., Lynch, J. P., and Brown, K. M. (1999). Ethylene: a regulator of root architectural responses to soil phosphorus availability. Plant Cell Environ. 22, 425-431. doi: 10.1046/j.1365-3040.1999.00405.x

Chacon-Lopez, A., Ibara-Laclette, E., Sanchez-Calderon, L., Gutierrez-Alanis, D., and Herrera-Estrella, L. (2011). Global expression pattern comparison between low phosphorus insensitive 4 and WT Arabidopsis reveals an important role of reactive oxygen species and jasmonic acid in the root tip response to phosphate starvation. Plant Signal. Behav. 6, 382-392. doi: 10.4161/psb.6.3.14160

Chadwick, A. V., and Burg, S. P. (1967). An explanation of the inhibition of root growth caused by indole-3-acetic acid. Plant Physiol. 42, 415-420. doi: 10.1104/pp.42.3.415

Chadwick, A. V., and Burg, S. P. (1970). Regulation of root growth by auxinethylene interaction. Plant Physiol. 45, 192-200. doi: 10.1104/pp.45.2.192 2014a) and the mechanism to counteract Fe toxicity is yet unknown.

\section{CONCLUDING REMARKS}

The recent knowledge on the role of ethylene in $\mathrm{P}_{\mathrm{i}}$ acquisition of higher plants demonstrates that ethylene is much more than just a modulator of root growth for adaptations to facilitate spatial $\mathrm{P}_{\mathrm{i}}$ acquisition. Increasing evidence points to numerous additional functions also in mechanisms for chemical $\mathrm{P}_{\mathrm{i}}$ solubilization in the rhizosphere and internal $\mathrm{P}_{\mathrm{i}}$ recycling. For future research activities in this context it will be important to demonstrate more in detail how ethylene is integrated into the signaling network mediating the respective $\mathrm{P}_{\mathrm{i}}$ starvation responses, to identify receptors and how it interacts with other hormonal and non-hormonal regulators (e.g., auxin, jasmonic acid, brassinosteroids, cytokinins, GA3, abscisic acid, polyamines, NO, miRNAs, sucrose). Particularly interesting in this context are also interactions with mechanisms for acquisition of other nutrients as indicated, e.g., for a potential link between $\mathrm{P}_{\mathrm{i}}$ acquisition and Fe acquisition in Arabidopsis and white lupin, which at least in case of white lupin share many similarities and even similar signaling pathways with ethyleäne as a modulator of both root growth responses and physiological adapatations for mobilization of $\mathrm{Fe}$ and $\mathrm{P}_{\mathrm{i}}$. Meanwhile it seems to be clear that ethylene-mediated $\mathrm{P}$ deficiency responses are not based on one general mechanism and considerable genotypic variation exists between plant species and cultivars, which needs to be characterized more in detail for potential exploitation in breeding programs.

Chevalier, F., Pata, M., Nacry, P., Doumas, P., and Rossignol, M. (2003). Effects of phosphate availability on the root system architecture: largescale analysis of the natural variation between Arabidopsis accessions. Plant Cell Environ. 26, 1839-1850. doi: 10.1046/j.1365-3040.2003. 01100.x

Chiou, T. J., and Lin, S. I. (2011). Signalling network in sensing phosphate availability in plants. Annu. Rev. Plant Biol. 62, 185-206. doi: 10.1146/annurevarplant-042110-103849

Cho, H. T., and Cosgrove, D. J. (2002). Regulation of root hair initiation and expansin gene expression in Arabidopsis. Plant Cell 14, 3237-3253. doi: 10.1105/tpc.006437

Dinkelaker, B., Hengeler, C., and Marschner, H. (1995). Distribution and function of proteoid roots and other root clusters. Bot. Acta 108, 183-200. doi: 10.1111/j.1438-8677.1995.tb00850.x

Dinkelaker, B., Hengeler, C., Neumann, G., Eltrop, L., and Marschner, H. (1997). "Root exudates and mobilization of nutrients," in Trees - Contributions to Modern Tree Physiology, eds H. Rennenberg, W. Eschrich, and H. Ziegler (Leiden: Backhuys Publishers), 441-452.

Forde, B., and Lorenzo, H. (2001). The nutritional control of root development. Plant Soil 232, 51-68. doi: 10.1023/A:1010329902165

Fukaki, H., and Tasaka, M. (2009). Hormone interactions during lateral root formation. Plant Mol. Biol. 69, 437-449. doi: 10.1007/s11103-00 8-9417-2

Gahoonia, T. S., Care, D., and Nielsen, N. E. (1997). Root hairs and phosphorus acquisition of wheat and barley cultivars. Plant Soil 191, 181-188. doi: 10.1023/A:1004270201418

Gardner, W. K., Barber, D. A., and Parbery, D. G. (1983). The acquisition of phosphorus by Lupinus albus L. III. The probable mechanism by which 
phosphorus movement in the soil/root interface is enhanced. Plant Soil 70, 107-124. doi: 10.1007/BF02374754

Gilbert, G. A., Knight, J. D., Vance, C. P., and Allan, D. L. (2000). Proteoid root development of phosphorus deficient lupin is mimicked by auxin and phosphonate. Ann. Bot. 85, 921-928. doi: 10.1006/anbo.2000.1133

Haling, R. E., Brown, L. K., Bengough, A. G., Young, I. M., Hallett, P. D., White, P. J., et al. (2013). Root hairs improve root penetration, root-soil contact, and phosphorus acquisition in soils of different strength. J. Exp. Bot. 64, 3711-3721. doi: $10.1093 /$ jxb/ert200

Hammond, J. P., and White, P. J. (2008). Sucrose transport in the phloem: integrating root responses to phosphorus starvation. J. Exp. Bot. 59, 93-109. doi: $10.1093 / \mathrm{jxb} / \mathrm{erm} 221$

Hammond, J. P., and White, P. J. (2011). Sugar signaling in root responses to low phosphorus availability. Plant Physiol. 156, 1033-1040. doi: 10.1104/pp.111.175380

He, C. J., Morgan, P. W., and Drew, M. C. (1992). Enhanced sensitivity to ethylene in nitrogen- or phosphate-starved roots of Zea mays L. during aerenchyma formation. Plant Physiol. 98, 137-142. doi: 10.1104/pp.98.1.137

He, C. J., Morgan, P. W., and Drew, M. C. (1994). Induction of enzymes associated with lysigenous aerenchyma formation in roots of Zea mays during hypoxia or nitrogen starvation. Plant Physiol. 105, 861-865.

Hindt, M. N., and Guerinot, M. L. (2012). Getting a sense for signals: regulation of the plant iron deficiency response. Biochim. Biophys. Acta 1823, 1521-1530. doi: 10.1016/j.bbamcr.2012.03.010

Hirsch, J., Marin, E., Floriani, M., Chiarenza, S., Richaud, P., Nussaume, L., et al. (2006). Phosphate deficiency promotes modification of iron distribution in Arabidopsis plants. Biochimie 88, 1767-1771. doi: 10.1016/j.biochi.2006. 05.007

Ho, C. H., Lin, S. H., Hu, H. C., and Tsay, Y. F. (2009). CHL1 functions as a nitrate sensor in plants. Cell 138, 1184-1194. doi: 10.1016/j.cell.2009.07.004

Holford, I. C. R. (1997). Soil phosphorus: its measurement, and its uptake by plants. Aust. J. Soil Res. 35, 227-239. doi: 10.1071/S96047

Ivanchenko, M. G., Muday, G. K., and Dubrovsky, J. G. (2008). Ethyleneauxin interactions regulate lateral root initiation and emergence in Arabidopsis thaliana. Plant J. 55, 335-347. doi: 10.1111/j.1365-313X.2008.03528.x

Jain, A., Poling, M. D., Karthikeyan, A. S., Blakeslee, J. J., Peer, W. A., Titapiwatanakun, B., et al. (2007). Differential effects of sucrose and auxin on localized phosphate deficiency-induced modulation of different traits of root system architecture in Arabidopsis. Plant Physiol. 144, 232-247. doi: 10.1104/pp.106.092130

Jeong, S. W., Das, P. K., Jeoung, S. C., Song, J. Y., Lee, H. K., Kim, Y. K., et al. (2010). Ethylene suppression of sugar-induced anthocyanin pigmentation in Arabidopsis. Plant Physiol. 154, 1514-1531. doi: 10.1104/pp.110. 161869

Kim, H.-J., Lynch, J. P., and Brown, K. M. (2008). Ethylene insensitivity impedes a subset of responses to phosphorus deficiency in tomato and petunia. Plant Cell Environ. 31, 1744-1755. doi: 10.1111/j.1365-3040.2008.01886.x

Kobayashi, H., and Saka, H. (2000). Relationship between ethylene evolution and sucrose content in excised leaf blades of rice. Plant Prod. Sci. 3, 398-403. doi: $10.1626 /$ pps.3.398

Lei, M., Zhu, C., Liu, Y., Karthikeyan, A. S., Bressan, R. A., Raghothama, K. G., et al. (2011). Ethylene signalling is involved in regulation of phosphate starvation-induced gene expression and production of acid phosphatases, and anthocyanin in Arabidopsis. New Phytol. 189, 1084-1095. doi: 10.1111/j.14698137.2010.03555.x

Lewis, D. R., Negi, S., Sulumar, P., and Muday, G. K. (2011). Ethylene inhibits lateral root development, increases IAA transport and expression of PIN3 and PIN7 efflux carriers. Development 138, 3485-3495. doi: 10.1242/dev. 065102

Li, Y. S., Gao, Y., Tian, Q. Y., Shi, F. L., Li, L. H., and Zhang, W. H. (2011). Stimulation of root acid phosphatase by phosphorus deficiency is regulated by ethylene in Medicago falcata. Environ. Exp. Bot. 71, 114-120. doi: 10.1016/j.envexpbot.2010.11.007

Li, Y.-S., Mao, X.-T., Tian, Q.-Y., Li, L.-H., and Zhang, W.-H. (2009). Phosphorus deficiency-induced reduction in root hydraulic conductivity in Medicago falcata is associated with ethylene production. Environ. Exp. Bot. 67, 172-177. doi: 10.1016/j.envexpbot.2009.05.013
Linkohr, B. I., Williamson, L. C., Fitter, A. H., and Leyser, H. M. (2002). Nitrate and phosphate availability and distribution have different effects on root system architecture of Arabidopsis. Plant J. 29, 751-760. doi: 10.1046/j.1365313X.2002.01251.X

Lopez-Bucio, L., Hernandez-Abreu, E., Sanchez-Calderon, L., Nieto-Jacobo, M. R., Simpson, J., and Herrera-Estrella, L. (2002). Phosphate sensitivity alters architecture and causes changes in hormone sensitivity in the Arabidopsis root system. Plant Physiol. 129, 244-256. doi: 10.1104/pp.010934

Lynch, J. P., and Brown, K. M. (2001). Topsoil foraging an architectural adaptation of plants to low phosphorus availability. Plant Soil 237, 225-237. doi: 10.1023/A:1013324727040

Lynch, J. P., and Brown, K. M. (2012). New roots for agriculture: exploiting the root phenome. Philos. Trans. R. Soc. B 367, 1598-1604. doi: 10.1098/rstb.2011.0243

Ma, Z., Bielenberg, D. G., Brown, K. M., and Lynch, J. P. (2001). Regulation of root hair density by phosphorus availability in Arabidopsis thaliana. Plant Cell Environ. 24, 459-467. doi: 10.1046/j.1365-3040.2001.00695.x

Marschner, H., Römheld, V., and Cakmak, I. (1987). Root-induced changes of nutrient availability in the rhizosphere. J. Plant Nutr. 10, 1175-1184. doi: $10.1080 / 01904168709363645$

Massonneau, A., Langlade, N., Léon, S., Smutny, J., Vogt, E., Neumann, G. et al. (2001). Metabolic changes associated with cluster root development in white lupin (Lupinus albus L.): relationship between organic acid excretion, sucrose metabolism and energy status. Planta 213, 534-542. doi: $10.1007 / \mathrm{s} 004250100529$

Miguel, M. A., Postma, J. A., and Lynch, J. (2015). Phene synergism between root hair length and basal root growth angle for phosphorus acquisition. Plant Physiol. 167, 1430-1439. doi: 10.1104/pp.15.00145

Mission, J., Raghothama, K. G., Jain, A., Jouhet, J., Block, M. A., Bligny, R., et al. (2005). A genome-wide transcriptional analysis using Arabidopsis thaliana Affymetrix gene chips determined plant responses to phosphate deprivation. Proc. Natl. Acad. Sci. U.S.A. 102, 11934-11939. doi: 10.1073/pnas.0505 266102

Nagarajan, V. K., and Smith, A. P. (2011). Ethylene's role in phosphate starvation signaling: more than just a root growth regulator. Plant Cell Physiol. 53, 277-286. doi: 10.1093/pcp/pcr186

Narayanan, A., and Reddy, B. K. (1982). "Effect of phosphorus deficiency on the form of plant root system," in "Plant Nutrition, Vol. 2, ed. A. Scaife (Slough: Commonwealth Agricultural Bureau), 412-417.

Negi, S., Ivanchenko, M. G., and Muday, G. K. (2008). Ethylene regulates lateral root formation and auxin transport in Arabidopsis thaliana. Plant J. 55, 175187. doi: $10.1111 /$ j.1365-313X.2008.03495.x

Neumann, G., and Martinoia, E. (2002). Cluster roots - an underground adaptation for survival in extreme environments. Trends Plant Sci. 7, 162-167. doi: 10.1016/S1360-1385(02)02241-0

Neumann, G., and Römheld, V. (2002). "Root-induced changes in the availability of nutrients in the rhizosphere," in Plant Roots The Hidden Half, 3rd Edn, eds Y. Waisel, A. Eshel, and U. Kafkafi (New York, NY: Marcel Dekker), 617-649.

Neumann, G., and Römheld, V. (2007). "The release of root exudates as affected by the plant physiological status," in The Rhizosphere: Biochemistryand Organic Substances at the Soil-Plant Interface, 2nd Edn, eds R. Pinton, Z. Varanini, and P. Nannipieri (Boca Raton, FL: CRC Press), 23-72.

Niu, Y. F., Chai, R. S., Jin, G. L., Wang, H., Tang, C. X., and Zhang, Y. S. (2012). Responses of root architecture development to low phosphorus availability: a review. Ann. Bot. 112, 391-408. doi: 10.1093/aob/mcs 285

O’Rourke, J. A., Yang, S. S., Miller, S. S., Bucciarelli, B., Liu, J., Rydeen, A., et al. (2013). An RNA-Seq transcriptome analysis of orthophosphate-deficient white lupin reveals novel insights into phosphorus acclimation in plants. Plant Physiol. 161, 705-724. doi: 10.1104/pp.112.209254

Philosoph-Hadas, S., Meir, S., and Aharoni, N. (1985). Carbohydrates stimulate ethylene production in tobacco leaf discs II. Sites of stimulation in the ethylene biosynthesis pathway. Plant Physiol. 78, 139-143. doi: 10.1104/pp. 78.1.139

Playsted, C. W. S., Johnston, M. E., Ramage, C. M., Edwards, D. G., Cawthray, G. R., and Lambers, H. (2006). Functional significance of dauciform roots: exudation of carboxylates and acid phosphatase under phosphorus deficiency in Caustis blakei (Cyperaceae). New Phytol. 170, 491-500. doi: 10.1111/j.14698137.2006.01697.x 
Popova, Y., Thayumanavan, P., Lonati, E., Agrochao, M., and Thevelein, J. M. (2010). Transport and signaling through the phosphate-binding site of the yeast Pho84 phosphate transceptor. Proc. Natl. Acad. Sci. U.S.A. 107, 2890-2895. doi: 10.1073/pnas.0906546107

Richardson, A. E. (1994). "Soil microorganisms and phosphorus availability," in Soil Biota: Management in Sustainable Farming Systems, eds C. E. Pankhurst, B. M. Doube, and V. V. S. R. Gupta (Clayton, VIC: CSIRO), 50-62.

Ruzicka, K., Ljung, K., Vanneste, S., Podhorska, R., Beeckman, T., Friml, J., et al. (2007). Ethylene regulates root growth through effects on auxin biosynthesis and transport-dependent auxin distribution. Plant Cell 19, 2197-2212. doi: 10.1105/tpc.107.052126

Sanchez-Calderon, L., Lopez-Bucio, J., Chacon-Lopez, A., Gutierrez-Ortega, A., Hernandez-Abreu, E., and Herrera-Estrella, L. (2006). Characterization of low phosphorus insensitive mutants reveals a crosstalk between low phosphorusinduced determinate root development and the activation of genes involved in the adaptation of Arabidopsis to phosphorus deficiency. Plant Physiol. 140, 879-889. doi: 10.1104/pp.105.073825

Schmidt, W., and Schikora, A. (2001). Different pathways are involved in phosphate and iron stress-induced alterations of root epidermal cell development. Plant Physiol. 125, 2078-2084. doi: 10.1104/pp.125.4.2078

Schweiger, P. F., Robson, A. D., and Barrow, N. J. (1995). Root hair length determines beneficial effect of a Glomus species on shoot growth of some pasture species. New Phytol. 131, 247-254. doi: 10.1111/j.14698137.1995.tb05726.x

Shane, M. W., De Vos, M., De Roock, S., and Lambers, H. (2003). Shoot P status regulates cluster-root growth and citrate exudation in Lupinus albus grown with a divided root system. Plant Cell Environ. 26, 265-273. doi: 10.1046/j.13653040.2003.00957.x

Smith, K. A., and Russell, R. S. (1969). Occurrence of ethylene, and its significance, in anaerobic soil. Nature 222, 769-771. doi: 10.1038/222769b0

Stepanova, A. N., Hoyt, J. M., Hamilton, A. A., and Alonso, J. M. (2005). A link between ethylene and auxin uncovered by the characterization of two rootspecific ethylene-insensitive mutants in Arabidopsis. Plant Cell 17, 2230-2242. doi: 10.1105/tpc.105.033365

Svistoonoff, S., Creff, A., Reymond, M., Sigoillot-Claude, C., Ricaud, L., Blanchet, A., et al. (2007). Root tip contact with low-phosphate media reprograms plant root architecture. Nature Genet. 39, 792-796. doi: $10.1038 / \mathrm{ng} 2041$

Swarup, R., Perry, P., Hagenbeek, D., Van Der Straeten, D., Beemster, G. T. S., Sandberg, G., et al. (2007). Ethylene upregulates auxin biosynthesis in Arabidopsis seedlings to enhance inhibition of root cell elongation. Plant Cell 19, 2186-2196. doi: 10.1105/tpc.107.052100

Thibaud, M. C., Arrighi, J. F., Bayle, V., Chiarenza, S., Creff, A., Bustos, R., et al. (2010). Dissection of local and systemic transcriptional responses to phosphate starvation in Arabidopsis. Plant J. 64, 775-789. doi: 10.1111/j.1365313X.2010.04375.x
Tsuchisaka, A., and Theologis, A. (2004). Unique and overlapping expression patterns among the Arabidopsis 1-amino-cyclopropane-1-carboxylate synthase gene family members. Plant Physiol. 136, 2982-3000. doi: 10.1104/pp.104.049999

Wang, B. L., Tang, X. Y., Cheng, L. Y., Zhang, A. Z., Zhang, W. H., Zhang, F. S., et al. (2010). Nitric oxide is involved in phosphorus deficiency-induced cluster-root development and citrate exudation in white lupin. New Phytol. 187, 112-112. doi: 10.1111/j.1469-8137.2010.03323.x

Wang, Z., Shen, J., Ludewig, U., and Neumann, G. (2015). A re-assessment of sucrose signalling involved in cluster root formation and function in phosphatedeficient white lupin (Lupinus albus L.). Physiol. Plant. 154, 407-419. doi: 10.1111/ppl.12311

Wang, Z., Straub, D., Yang, H., Kania, A., Shen, J., Ludewig, U., et al. (2014a). The regulatory network of cluster-root function and development in phosphatedeficient white lupin (Lupinus albus) identified by transcriptome sequencing. Physiol. Plant. 151, 323-338. doi: 10.1111/ppl.12187

Wang, Z., Moshiur Rahman, A. B. M., Wang, G., Ludewig, U., Shen, J., and Neumann, G. (2014b). Hormonal interactions during cluster root development in phosphate-deficient white lupin (Lupinus albus L.). J. Plant Physiol. 177, 74-82. doi: 10.1016/j.jplph.2014.10.022

Ward, J. T., Lahner, B., Yakubova, E., Salt, D. E., and Raghothama, K. G. (2008). The effect of iron on the primary root elongation of Arabidopsis during phosphate deficiency. Plant Physiol. 147, 1181-1191. doi: 10.1104/pp.108.118562

Zaid, H., El Morabet, R., Diem, H. G., and Arahou, M. (2003). Does ethylene mediate cluster root formation under iron deficiency? Ann. Bot. 92, 673-677. doi: $10.1093 / \mathrm{aob} / \mathrm{mcg} 186$

Zhang, Y. J., Lynch, J. P., and Brown, K. M. (2003). Ethylene and phosphorus availability have interacting yet distinct effects on root hair development. J. Exp. Bot. 54, 2351-2361. doi: 10.1093/jxb/erg250

Zhang, Z., Liao, H., and Lucas, W. J. (2014). Molecular mechanisms underlying phosphate sensing, signaling, and adaptation in plants. J. Integr. Plant Biol. 56, 192-220. doi: 10.1111/jipb.12163

Zhou, K., Yamagishi, M., Osaki, M., and Masuda, K. (2008). Sugar signalling mediates cluster root formation and phosphorus starvation-induced gene expression in white lupin. J. Exp. Bot. 59, 2749-2756. doi: 10.1093/jxb/ern130

Conflict of Interest Statement: The author declares that the research was conducted in the absence of any commercial or financial relationships that could be construed as a potential conflict of interest.

Copyright (C) 2016 Neumann. This is an open-access article distributed under the terms of the Creative Commons Attribution License (CC BY). The use, distribution or reproduction in other forums is permitted, provided the original author(s) or licensor are credited and that the original publication in this journal is cited, in accordance with accepted academic practice. No use, distribution or reproduction is permitted which does not comply with these terms. 